\title{
雚 University of Glasgow
}

McMenemy, D. (2022) Internet access and bridging the digital divide: the crucial role of universal service obligations in telecom policy. In: Smits, M. (ed.) Information for a Better World: Shaping the Global Future. Series: Lecture Notes in Computer Science, 13192. Springer: Cham, pp. 122-134. ISBN 9783030969561

(doi: 10.1007/978-3-030-96957-8_12)

This is the Author Accepted Manuscript.

There may be differences between this version and the published version. You are advised to consult the publisher's version if you wish to cite from it.

http://eprints.gla.ac.uk/265795/

Deposited on: 24 February 2022

Enlighten - Research publications by members of the University of Glasgow http://eprints.gla.ac.uk 


\title{
Internet access and bridging the digital divide: the crucial role of universal service obligations in telecom policy
}

\author{
David McMenemy ${ }^{[0000-0002-3203-9001]}$ \\ ${ }^{1}$ Strathclyde iSchool Research Group, University of Strathclyde, Glasgow, Scotland \\ Information Studies, University of Glasgow, Glasgow, Scotland (from Jan 2022) \\ d.mcmenemyestrath.ac.uk
}

\begin{abstract}
With Internet access increasingly a vital element of day to day life, this paper explores the concept of the universal service obligation (USO) in telecommunications law and policy, and considers the arguments for it to be expanded in the digital age to include access to broadband as a fundamental right. It considers aspects of United States, European Union, and United Kingdom policy to consider the digital inclusion limitations of a legal concept that was created in an analogue time. Highlighting the increasing use of broadband and mobile telephony, the paper argues for a broader concept of universal service to emerge to help connect the digitally excluded and let them take their rightful place as digital citizens.
\end{abstract}

Keywords: telecommunications policy, broadband, universal service, equity of access

\section{Introduction}

The concept of universal service with regards to access to critical utility services emerged to ensure that essential services were available to all in a basic package and that all in society would be able to reap the benefits of emerging utilities. In other words "to ensure access to services that had become fundamental social and economic tools" was easily available to all [1, p.152]. The key to universal service is understanding the notion that the benefits to society and individuals that arise out of access to such services, "outweigh the cost of provision" [2, p.469]. This might mean that the market may have to be governed by increased state regulation to ensure a minimum level of service is guaranteed to at an affordable price. In that context, universal service obligations (USO) have been applied to policy goals in several utility service markets such as electricity and gas, water, mail, as well as telecommunications. As Simon informs us, the concept of universal service "is grounded in different legal and economic traditions on either side of the Atlantic" [3, p138]. This difference in approach on a global 
basis is clearly evident with regards to the range of views that can be seen on the importance of including broadband and mobile services within the definition of universal service [4]. However, the EU has rightly recognized that ICTs provide immense possibilities for economic and social growth, with "power for the transformation of economic, social and political life" [5, p.25].

This paper will begin by exploring the components of universal service in telecommunications policy and what they seek to achieve. It will then examine how that concept as a policy dynamic is played out, and consider whether current definitions of universal service are fit for purpose in the modern era, or whether we need to expand our commitment to new and emerging technologies within the remit of the term.

\section{The scope of universal service}

Universal access was first defined as a concept in the US telecommunications market in 1910 when the AT \& T President called for a universal and extensive telephony system for all, before being confirmed in US law in the Communications Act 1934. More specifically in the modern era, it relates to a "diverse set of initiatives to subsidize communications services in contexts where such services would otherwise not be provided at all" [6, p.295]. The prohibitive nature of providing services in these contexts is usually economic: high costs in delivering the infrastructure that cannot realistically be recouped, and/or not enough of a customer base to justify the expenditure.

This leads to a key policy element of universal access, namely that providing it usually entails government subsidy to incentivize the telecommunications companies to undertake infrastructural projects that support it. As we will see, policymakers see telecommunications policy as a vital arm in enhancing many aspects of public policy, and the cases we will discuss in this paper highlight the diversity and importance of universal access in fulfilling key government policy objectives.

\subsection{Examples from the United States}

The Telecommunications Act 1996 affirmed the importance of universal access in the minds of American policy-makers. Section 254 (b) of the Act focuses on the principles of universal access, and states 6 key principles that underpin it:

1. Quality and rates

2. Access to advanced services

3. Access in rural and high-cost areas

4. Equitable and non-discriminatory contributions

5. Specific and predictable support mechanisms

6. Access for schools, health care, and libraries

For the purposes of this paper, principle 3 states, "Consumers in all regions of the Nation, including low-income consumers and those in rural, insular, and high-cost areas, should have access to telecommunications and information services... that are reasonably comparable to those services provided in urban areas" [7]. Written into policy, 
these principles compelled the Federal Communications Commission (FCC) to implement several programs to achieve them:

- The federal Lifeline and Link-Up programs: needs-based subsidy programs for lowincome households. Lifeline, established in 1985 , provides a $\$ 9.25$ monthly discount for eligible subscribers, with up to $\$ 34.25$ a month for eligible subscribers on tribal lands. This was extended to cell phone services in 2005.

- The High-Cost fund: a non-needs based fund aimed at keeping consumer costs low in mostly rural areas] set up in 1997

- The E-rate program which was initiated in 1997 and provided funding for broadband facilities in schools and libraries. This was expanded in 2014 to promote wi-Fi in schools and libraries

- A similar program to E-rate for rural health care facilities launched in 1997 [6, p.296].

Nuechterlein and Weise evaluated the High-Cost fund, which by 2010 had accounted for $\$ 4.6$ billion dollars in government investment, and highlighted two key concerns. Firstly, that for much of the period between 1996 and 2010 it focused on subsidising telephone lines rather broadband, a policy they considered anachronistic. Secondly that due to an over-emphasis on competition, multiple service providers were supported to provide services in rural areas, rather than focusing all subsidies on one company to keep costs down [6, p.296]. The program was re-evaluated and re-launched in 2012 as the Connect America Fund with a re-definition of its mission as to include voice and broadband services in its strategic focus. Its renewed focus including 5 key universal service obligations:

- Preserve and Advance Voice Service

- Ensure Universal Availability of Voice and Broadband to Homes, Businesses, and Community Anchor Institutions

- Ensure Universal Availability of Mobile Voice and Broadband where Americans Live, Work, or Travel

- Ensure Reasonably Comparable Rates for Broadband and Voice Services

- Minimize Universal Service Contribution Burden on Consumers and Businesses [8].

Latest statistics indicate that nationally across the United States, $96 \%$ of households have a fixed lined telephony connection, and $77 \%$ of households have a high-speed broadband connection. The re-emphasis of the program, then, does seem valid if universal service around broadband access is to come close to that of fixed lined telephony.

Hauge et al examined the Lifeline program aimed at low-income households and found it wanting. Their data revealed that low-income households were increasingly moving towards mobile telephony for their communications and information needs, while the subsidized programs such as Lifeline were over- focused on fixed telephony services. As they suggest, this is a problem because "US universal service policy has not changed to reflect the rise in mobile penetration" [9, p.130]. Since the Telecommunications Act states that universal service should be to consider, "an evolving level 
of telecommunication services that the FCC shall establish periodically...taking into account advances in telecommunications and information technologies and services" there was scope here to expand the definitions of universal service beyond old paradigms of fixed telephony services. This occurred in March 2016 with the restructuring of the program to include broadband access within the Lifeline initiative [10]. The initiative was now to provide support for mobile or fixed broadband as standalone services, without the need to include telephony services. Importantly it also specified minimum universal service standards for both mobile broadband and mobile telephony services. Given the findings of Hauge et al that the voice needs of consumers were increasingly being met by mobile telephony, the inclusion within the program of mobile services seemed both logical and timely.

The E-rate program to provide a universal service to schools and libraries has arguably been a great success, however. In 1996 when the initiative began, only 14\% of schools were connected to the Internet, and now "virtually all" are connected [11]. Even here, however, we can see the impact of notions of what universal service should encompass evolving. As technology improves the need for schools and libraries to access super speed lines is of paramount importance if modern learning technologies are to be adopted; yet this progress is largely hindered if the institutions' access is via traditional copper cabling and not fiber optic cabling. The statistic that " $31 \%$ of urban public schools and $41 \%$ of rural public schools do not have access to fiber facilities" highlights that the limitations of the old telephonic infrastructure arguably hinder progress and development [12].

\subsection{Reflection on global universal service obligations}

While this paper focused on the USA, UK, and EU, it is important to note that the case for universal service reform is not one that is universally agreed upon among countries around the globe. In a recent report, the OECD dealt with the debates around the inclusion of broadband coverage within universal obligations specified by countries [4]. In its summary of the worldwide commitments to universal service, it emphasized that "In some cases, the inclusion of mobile telephony in the scope of universal service obligations could lead to better coverage and reception" [4, p.5]. In a hint too that an update to the concept of universal service was perhaps overdue, it suggested that reflections on it were aiming to, "establish whether some of the services currently guaranteed through universal service obligations no longer need to be supported through this means, and vice versa" $[4, p .5]$.

Nevertheless, the complexity of the global situation was well summarized by Garcio Calvo in her 2013 report:

A number of countries including the United States, Israel, Finland, Malta, Spain and Switzerland have already taken steps to include broadband Internet service as part of their existing universal service obligations. Other countries like Korea, Japan, the United Kingdom and Australia have developed strategies to ensure broadband "availability for all" through other universal service policies. A third group including, Denmark, Norway, Germany, The Netherlands and Ireland has 
opted not to support broadband through either inclusion in universal service obligations or other commitments to provide broadband for all [4, p.16].

This global complexity does not negate the fact that essentially the requirements of universal service as specified pre the internet revolution no longer satisfy the requirements and the needs of consumers. If rural and disadvantaged communities are to benefit from the development of the new technologies, then the costs wasted on installing an old infrastructure must be weighed against the costs of providing one for the needs of the $21^{\text {st }}$ century. This may entail news ways of thinking, for as Garcio Calvo highlights, many initiatives "were designed to cover relatively small gaps derived from fulfilling universal service obligations over existing networks, not to deploy new infrastructure" $[4, \mathrm{p} .4]$.

The context of universal service in European telecommunications policy is laid out in Directive 2002/22/EC (Universal Service and Users' Rights Directive) and the updated 2009/136/EC (Citizens' Rights Directive). Article 8 of 2002/22/EC states that the "fundamental requirement of universal service is to provide users on request with a connection to the public telephone network at a fixed location, at an affordable price" [13]. Article 10 allows Member states some latitude with regards to defining the affordable price based on specific conditions within the member state. The focus in 2002/22/EC is also related to the availability of public payphones, as well as ensuring disability is considered regarding accessibility.

\subsection{The key elements of universal service}

Garcia Calvo discusses universal service in an international context in a report for OECD, and she summarizes the key elements of USO in the telecommunications sector as:

- Availability: that the level, price and quality of service is equivalent wherever a person lives or conducts business so that residing in a rural or remote area does not affect a person's ability to access communication services.

- Affordability: that maintaining and using the service does not place an unreasonable burden on consumers, particularly vulnerable or disadvantaged consumers.

- Accessibility: that a person with a disability can use the service so that a person's level of physical and mental ability does not exclude them from access to communication services $[4$, p.9].

These goals are largely economic, and the social inclusivity aspects of them primarily relate to accessibility and access issues, without exploring the wider societal elements; arguably they focus on process rather than any grander notions of the use citizens can put the systems to. Milne and Feijoo offer three policy elements that they believe underpin the concept of universal service:

- economic (promoting economic efficiency and growth),

- social (achieving or maintaining social cohesion), and 
- political (offering all citizens equitable opportunities) [14, p.166].

We will see these elements occur throughout the paper as we discuss European experiences, but it is important to note this expanded aspect of universal service as encompassing both social and political elements in addition to the economic. Therefore, from the citizen perspective, we can elicit from our discussion of the concept of universal service two key elements that underpin it. These are:

7. Facilitating communication and inclusion

8. Enhancing the economy

We will utilize these aspects in our discussion of emerging services to decide if universal service definitions need to be expanded.

\section{Emergence of new telecommunications services}

We will now move on to discuss the European dimension to universal service in a broader sense, with a focus on the particular situation in the UK. As OFCOM have observed, efficient and speedy Internet access "is already necessary for social and economic cohesion, and will become increasingly important as more services move online and new applications come to the market" [15].

The key issue with regards reconsidering the USO around telecommunication services is the convergence of services that has occurred in the information society [16]. The infrastructure and technologies that were designed to carry voice services have been revolutionized and now carry data. This simple explanation hides a multitude of complexity: data services have evolved from simple text-based services that emerged in the 1970s and 1980s to now include multimedia and entertainment services, and egovernment and social media services. As Batura has argued, "the infrastructure which carries information and enables communication has become much more of a valuable asset than ever before and an indispensable precondition for success and development in the information society" [5, p.24]. There is, thus, an argument for saying that a USO that guaranteed voice access no longer embraces the complexity of the kinds of access and potential that telecommunications services offer.

\subsection{The United Kingdom experience}

Statistics from the Office of National Statistics reveal that UK citizens have embraced new technologies and Internet applications with great gusto. In $2020,96 \%$ of the UK population had access to the Internet, with $46.6 \%$ using it daily. $70 \%$ used the access to access news, while $60 \%$ used it to access health information [17]. Meanwhile, the 2010 s has been dubbed the "decade of the smartphone" [18] with $78 \%$ of the UK population claiming use of a smartphone in 2018, compared to $27 \%$ in 2011. Also in 2018, $76 \%$ of mobile phone users utilize the handsets to access the Internet, consuming an average of $1.9 \mathrm{~GB}$ of data per month [18]. 
These statistics present a picture of a telecommunications infrastructure that is changing regarding its usage; the idea of a landline for telephony purposes is increasingly becoming a thing of the past, and it is the broadband aspect that is increasingly becoming a crucial element of digital inclusion. Other recent research in the UK supports this notion and has indicated that consumers believe the ability to do away with the cost of paying for a landline for Internet access would be a money-saver for them, a net saving of around $£ 2$ a week. The respondents in the research concluded that the need for a landline was vastly diminishing and the need for telephony services and Internet access could be met via a mobile phone and Internet dongle.

The UK government has recently moved to expand the USO to include broadband access. A consultation was launched in the spring of 2016 aimed at eliciting views of citizens and organisations on how best to move forward with the idea. However, the government clearly stated its desire to develop a minimum USO of 10MBPS: "10Mbps enables full participation in our digital society - watching video on demand, listening to internet radio or streamed music, using social media, accessing Government services, shopping online and working from home" [19]. The list of services provided in the quote from the DCMS consultation indicates the aspects of life the government recognizes broadband access as supporting:

- Entertainment: increasingly entertainment services are streamed, including BBC and ITV players, in addition to Netflix, Amazon Prime and the like. Even when consumers do not subscribe to commercial services, they finance BBC services like iPlayer through the license fee and thus has a legitimate expectation to be able to utilise the service.

- Social interaction: social media, VOIP, Skype and the like are facilitated by good broadband access, and the ability of broadband to significantly enhance the communicative aspects of telecommunication services is significant

- Interaction with government: e-government allows services to be accessed online, but also enables interaction with elected representatives and officials. Such vital services such as applying for benefits are now exclusively online

- E-commerce: both as consumer and provider, the ability of citizens to undertake their buying and selling online is a fundamental aspect of economic development. Broadband allows new business to emerge where access is sufficient, as will be highlighted below

- Teleworking: capacity to work from home and continue to undertake business supports the economy, as well as taking pressure off transport infrastructure, and enables connectedness with the family and community

These services can be argued to be important aspects of digital citizenship, and thus there is a substantial justification for expanding USO to enable them to occur.

In a Scottish context, there is a critical focus on expanding broadband access to rural areas and other socially excluded groups. While telecommunications policy remains a reserved issue dealt with by the Westminster government, there is also a need for the Scottish Government to focus on the expansion of digital infrastructure within Scotland to aid inclusion and growth. The Digital Scotland initiative focuses on four key themes: 
- Connectivity

- Digital economy

- Digital participation

- Digital public services [20].

To that end, it follows closely the key issues of universal service defined earlier by Mile and Feijoo. Nevertheless, a USO for broadband could be an expensive undertaking in areas like the Highlands of Scotland, and speeds of 10MBPS as suggested by the UK government would likely rely on significant state subsidy, let alone the 30MBPS recommended by the EU Digital Agenda. In the feedback to OFCOM related to the UK government consultation in 2016, it was clear the broadband industry were concerned about a USO obligation that was economically onerous [15]. A USO that was able to include rural and highland areas suitably, then, would need to be looked at carefully for economic viability.

Some major initiatives have been seen to promote inclusive connection programs within the UK. Programs like Digital Glasgow aim to build both infrastructure and skills within the community to enable society to benefit from the technological revolution, and aspects of it include initiatives like citywide free Wi-Fi [21]. Programs like this are replicated throughout the UK and usually work as a partnership between public, private and third sectors. The potential issues on relying on such initiatives to facilitate universal access to internet services is the reliance on what can often be a sub-standard network. While free citywide Wi-Fi provides a safety net for citizens, and an incentive for tourists and visitors, the public nature of it raises issues of security and privacy for users. It is important that any safety net services do not compromise on privacy and they, therefore, do not provide a suitable proxy for a USO aimed at individual citizens.

\section{Justification for the expansion of universal service}

The emergence of new telecommunications services such as broadband and mobile telephony has clearly transformed society, and the telecommunications industry. We have already discussed the experiences in the UK, and we can posit a strong argument that universal service should be expanded to include the array of emerging services that are continuously evolving into the digital marketplace. As Feijoo and Milne argue, "The current model revolving around the provision of well-defined "services" (e.g. fixed voice) appears in need of fundamental re-thinking" [22, p.4].

Revisiting our earlier categories that underpinned the concept of universal service, we will now attempt to justify the argument for expansion of USOs to broadband services by providing a discussion around the concepts of facilitating communication and inclusion, and enhancing the economy. The original vision for universal service for telephone services was deemed important to enable citizens to have access to a technology that allowed them to communicate with each other across regions, countries, and continents. This noble goal is clearly one that high-speed Internet access transforms exponentially since it allows communication to be undertaken in numerous ways. While voice remains straightforward, whether via the existing fixed line or as VOIP, the ability add video communications enhances the communication experience 
significantly. The evolution of new communication mediums such as social media services has enabled interactions in previously unexplored ways, even allowing celebrities and politicians to be able to communicate with their fans and electors.

Whether in the form of re-connecting families and friends, or facilitating business interaction, the communicative elements of broadband transcend what is possible via fixed telephone lines and on their own could arguably justify the expansion of the USO to broadband services.

\subsection{Facilitating communication and inclusion}

The original vision for universal service for telephone services was deemed important to enable citizens to have access to a technology that allowed them to communicate with each other across regions, countries, and continent. This noble goal is clearly one that high-speed Internet access transforms exponentially since it allows communication to be undertaken in numerous ways. While voice remains straightforward, whether via the existing fixed line or as VOIP, the ability add video communications enhances the communication experience significantly. The evolution of new communication mediums such as social media services has enabled interactions in previously unexplored ways, even allowing celebrities and politicians to be able to communicate with their fans and electors.

Whether in the form of re-connecting families and friends, or facilitating business interaction, the communicative elements of broadband transcend what is possible via fixed telephone lines and on their own could arguably justify the expansion of the USO to broadband services.

\subsection{Enhancing the economy}

The economic benefits of high-speed broadband services are many-faceted. As identified by the UK government in its proposal to expand the USO obligation, the digital economy presents significant opportunities for the emergence of new companies and services. The ability for new services to emerge is heavily reliant on the capacity to do business online in an efficient manner, and many companies rely on high bandwidth to achieve this. While this might not be an issue in areas covered by high-speed networks, the ability for rural areas to expand their economies within the digital economy remain restricted if high-speed access is not made available to them.

The UK case study dubbed Cybermoor provides a good picture of the potential for high-speed broadband to transform a rural area. Utilising a long-range radio-based broadband solution, the community of Alston Moor was able to provide high-speed access of $10 \mathrm{MB}$ plus to all in the community, enabling skills and educational benefits as well as economic. As the case study states:

In a perfect example of how broadband connectivity can empower people to change their economic status, one resident moved his business from the South East of England to Alston Moor. Due to the extremely low cost of office space and connectivity, he was able to cost-effectively run a global business from a refurbished farm [23]. 
Notwithstanding the benefits to the individuals who was able to run his business by moving more effectively, the opportunity also allowed business types that were previously not able to be based in the area to thrive there.

The faster the broadband access in rural and excluded areas, the more diverse opportunities that can manifest regarding economic benefits. The connection of the village of Exminster in Devon to high-speed broadband allowed a local photographer to transform his business and be able to transmit and download large file sizes that are the basic stuff of digital image work [24]. He can email clients images quickly, and can access any software downloads he needs to undertake his work in a fast and cost-efficient way.

\subsection{Keeping the status quo?}

The status quo with regards to USO in telecom services no longer seems an option. As Cave and Hatta argue, "the spread of mobile technologies is displacing the traditional fixed network as the natural or only means of discharging USO, and this justifies full technological neutrality in allocating and discharging USO" [25]. It simply no longer seems plausible to argue that the wide diffusion of broadband access within developed countries, and the services that rely on broadband access to be viable, does not constitute a prima facie case for the expansion of a USO to broadband. While this growth has been exponential, it remains the case that the penetration of broadband and the design of increasingly bandwidth-hungry services to utilize its benefits result in those without access to high-speed networks being excluded from large swathes of modern society. Whether this USO fixes on fixed line solution, or more realistically a mixed solution incorporating fixed line, mobile, and satellite services, the need for a USO that guarantees high-speed access to all is long overdue.

Nevertheless, Simon offered some words of caution when discussing the potential of developing broadband access as a USO in 2008:

Lessons of history clearly show that the deployment of a network requires considerable time and that during this period there is an enduring discrepancy between social but theoretical goals and the reality of what the market can provide under normal economic conditions. To try to close the gap by adding social obligations and redistributing revenues may have some political appeal but will add extra costs as well as negative incentives [3, p.146].

There is a real politick element, in that commitment to the admirable goal of a full USO around adequate high-speed access for all is not something that can be achieved overnight. Commitment from both a political and an industry standpoint is an absolutely vital element in expanding broadband services, and expectation management within rural communities may also need to be handled sensitively. There are real challenges in providing access to some remote or challenging locations that may need innovative solutions to overcome. 


\subsection{Other considerations: spectrum allocation and net neutrality}

While the space does not exist in this paper to discuss them in detail, other telecommunications issues also impact on equity of access and need to be given due consideration. As argued by Cave and Matta, the importance of spectrum management in mobile telecommunications is a vital aspect of any potential mobile USO [25, p.63]. Spectrum allocation relates to the management of mobile telephony spectrums within countries and regions, and usually involves those countries or regions auctioning off mobile network space to telecom companies to use and charge consumers. These licenses to use the spectrum are usually enormously expensive, therefore an argument can be made that if the companies are seeking to recoup these costs, a compelled USO may well lead to companies not wishing to bid for the licenses and/or invest in innovative new services. One solution to this is, of course, for governments to subsidize companies who provide a USO for mobile services, but the dangers of this are clear from the point of view of ensuring that any mobile USO is not a second-class service due to lack of investment or high quality companies providing them.

Similarly the concerns over net neutrality are also a consideration for a comprehensive USO policy in the digital age. Net neutrality is the principle that an internet service provider should provide access to all contents without fear or favor, and not prioritize their own market interests in delivering content. Yet Glass and Tardiff highlight that notions of a separation between telecommunications services and information services is an outdated way of looking at the world in the modern era [26, p.201]. It is no accident that telecommunications companies increasingly became buyers of digital content creators throughout the 1990s and into the modern age, and also began to create their own content to deliver via their networks, with a view to enticing subscribers to their own networks. In the UK, for instance, BT launched a BT Sport channel in 2013, free to their own subscribers. In a move from the opposite end of the room, satellite broadcaster Sky Television got into the telecom business in 2005 by buying the Internet Service Provider EasyNet. Such moves are typical of those seen across other countries and are designed to be able to package content and telephony services in one package while privileging their own subscribers. Such moves are clearly a concern in terms of a USO spirit, and need to be monitored closely to ensure digital citizens do not see themselves disenfranchised from key services because they cannot afford the services of a particular telecom provider.

\section{Conclusions}

This paper has explored the concept of universal service in policy terms and argued that the concept needs to be expanded to include emerging mobile and broadband services and that existing commitments to fixed telephony USOs should be regularly re-evaluated in the light of the significant reduction in usage of such services. If a genuinely inclusive information society is to emerge, and the benefits of the telecommunication services that are developing are to be for the advancement of all, then we must seek to ensure that old technologies and policy commitments to them, however noble, are updated for the modern era. Batura argues that: 
A comprehensive examination of different electronic communications services is necessary in the context of their importance for the life and participation in the Information Society. It needs to be taken into account that in the Information Society process of communication and access to means of communication become disproportionally decisive for all societal activities [5, p.31].

As we have discussed, the concept of universal service was defined in an era before the Internet was conceived as a tool for citizens to communicate. The universal service concept was relatively static for decades, as telephony itself remained a simple issue of voice services over a fixed telephone line. In that vein, Milne and Feijoo offer that:

We are no longer talking just about plain old telephones, but also about personal digital assistants, multifunctional mobile phones, computers, digital televisions - and their associated networks, modes of connectivity and skills. Any universal service regulation has to take account of these varying preferences [14, p.167].

The emerging services we have seen on the Internet, and technologies needed to access them, have grown exponentially, and it may be the case that the policy principles that underline 21 st century USOs need to be revisited on a much more regular basis than in the past. The logistical and policy-formulation elements of this present a challenge, but it is one that governments have to address if citizens are to be able to take their place in and benefit from the Information Society. As has been observed, the expansion of Internet services and the technologies that support them are "regarded by OECD policy makers as a critical foundation for sustainable economic growth and prosperity" [4]. Such a recognition needs to be met by governments with increased focus on action, to cement affordable access to such services as a cornerstone of modern USOs and to enhance digital citizenship and economic development within communities.

Policies relating to universal access are now focusing more on broadband and mobile services to efficiently harness both the advantages of the emerging technologies, and the significant investments made by governments. The recent commitments from both the US and the UK governments to develop a universal service obligation for broadband is a welcome step towards a re-definition of the concept for the 21 st century.

\section{References}

1. Blackman C and Forge S, 'The future of universal service in Europe' (2008) 10 info p.152

2. Wild $\mathrm{C}$ and others, Electronic and Mobile Commerce Law: An analysis of trade, finance, media and cybercrime in the digital age (University Of Hertfordshire Press 2011) p.469.

3. Simon JP, 'Universal service: between socio-political mythology and economic reality - an international cross comparison EU-USA of the regulatory-economic framework' (2008) 10 info p. 138

4. Garcia Calvo A, Universal Service Policies in the Context of National Broadband Plans (OECD Digital Economy Papers, No 203, 2013)

5. Batura $\mathrm{O}$, 'Universal service in the EU information society policy' (2014) 16 info 24 p.25. 
6. Nuechterlein JE and Weise PJ, Digital Crossroads : Telecommunications Law and Policy in the Internet Age. p.295.

7. Telecommunications Act 1996

8. Connect America Fund Portal. https://www.fcc.gov/general/connect-americ fund-progressportal

9. Hauge JA, Chiang EP and Jamison MA, (2009) 33 Telecommunications Policy p.129-145

10. FCC MODERNIZES LIFELINE PROGRAM FOR THE DIGITAL AGE. https://apps.fcc.gov/edocs_public/attachmatch/DOC-338676A1.pdf

11. Universal Service Program for Schools and Libraries (E-Rate) https://www.fcc.gov/general/universal-service-program-schools-and-libraries-e-rate

12. WIRELINE COMPETITION BUREAU AND OFFICE OF STRATEGIC PLANNING AND POLICY ANALYSIS https://apps.fcc.gov/edocs_public/attachmatch/DOC330505A1.pdf

13. DIRECTIVE 2002/22/EC OF THE EUROPEAN PARLIAMENT AND OF THE COUNCIL of 7 March 2002 on universal service and users' rights relating to electronic communications networks and services (Universal Service Directive)

14. Milne $\mathrm{C}$ and Feijoo C, 'Re-thinking universal service policy for the digital era: Editors' conclusions' (2008) 10 info p.166

15. OFCOM, Designing the broadband universal service obligation: summary of responses to the calls for inputs. (2016)

16. Xavier P, 'From universal service to universal network access?' (2008) 10 info 20

17. Office for National Statistics. Internet access - households and individuals, Great Britain: 2020.

18. OFCOM, Communications Market Report 2018.

19. Davis A, Hirsch D and Padley M, A Minimum Income Standard for the UK in 2014 (Joseph Rowntree Foundation 2014) p.18.

20. Digital Scotland: Scotland's Digital Future http://www.gov.scot/Topics/Economy/digital

21. Digital Glasgow. https://www.glasgow.gov.uk/index.aspx?articleid=17711

22. Feijoo $\mathrm{C}$ and Milne $\mathrm{C}$, 'Re-thinking universal service policy for the digital era: setting the scene - an introduction to the special issue on universal service' (2008) 10 info p.4.

23. Cybermoor. http://www.ukbroadband.com/case-studies-remote-areas

24. Connecting Somerset and Devon - Case Studies https://www.connectingdevonandsomerset.co.uk/faster-broadband-for-business/case-studies/

25. Cave M and Hatta K, 'Universal service obligations and spectrum policy' 10 info (2008) p.62.

26. Glass, V., \& Tardiff, T. A new direction for the net neutrality debate. 43(3) Telecommunications Policy p.199 